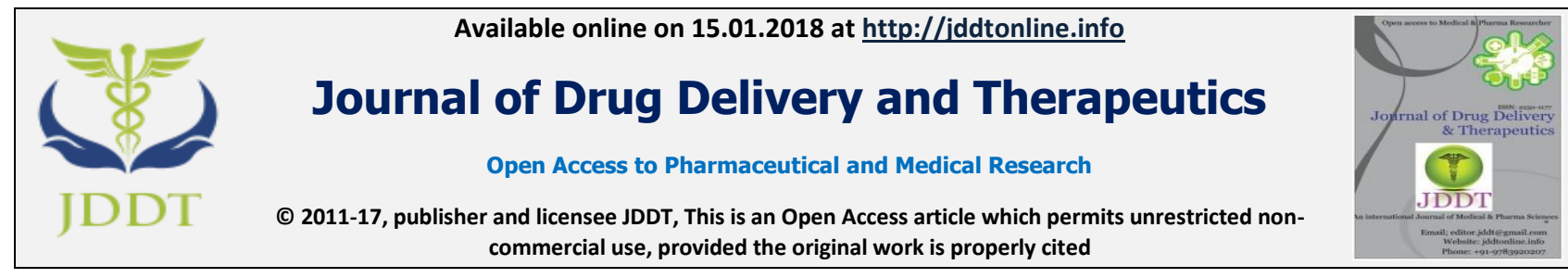

Open $\odot$ Access

Research Article

\title{
COMPARATIVE IN VITRO EVALUATION OF BRANDS OF CLOTRIMAZOLE CREAM FORMULATIONS MARKETED IN ETHIOPIA
}

\author{
Dereje Debebe, Tesfaye Gabriel*, Yonas Brhane, Abraham Temesgen, Muluken Nigatu, Tesfa Marew \\ Department of Pharmaceutics and Social Pharmacy, School of Pharmacy, College of Health Sciences, Addis Ababa, University, \\ Addis Ababa, Ethiopia
}

\begin{abstract}
The aim of present work was to undertake comparative in vitro quality evaluation of six marketed clotrimazole cream formulations in Ethiopia with respect to physico-chemical properties like viscosity, spreadability, extrudability, $\mathrm{pH}$ and drug content. In vitro clotrimazole release from cream formulations was also studied using synthetic cellulose acetate membrane at $37{ }^{\circ} \mathrm{C}$ in a solvent containing methanol and PBS 7.4 in the ratio of 75:25 as receiver medium. The cumulative amounts of the drug released over $12 \mathrm{~h}$ $\left(\mu \mathrm{g} \mathrm{mm}{ }^{-2}\right)$ were analyzed. All clotrimazole cream formulations showed good and smooth homogeneous appearance with white color. The $\mathrm{pH}$ of clotrimazole cream formulations ranged from 4-7, which is a physiologically acceptable $\mathrm{pH}$ range and in principle devoid of any skin irritation. Clotrimazole content ranged from 90-110\%, ensuring the uniformity of the drug content in all formulations. The increase in diameter of clotrimazole cream formulations following the spreadability test was found to range from 4-6 cm. Cream formulation D (Clotri-Denk) exhibited highest viscosity values than other formulations, whereas formulation E (Chinese Clotrimazole BP) showed lowest viscosity value. Cream formulation F (Mycoril) showed better extrudability and spreadability as compared to other formulations. Drug release from all formulations was slow in the first $6 \mathrm{hrs}$. After the $6^{\text {th }}$ hr, steady drug release continued for formulation D and E. Fast drug release was observed in formulations A (Candid) and B (Candigen), whereas for the formulations $\mathrm{C}$ (Canesten), D and E, steady drug release pattern was observed after the $6^{\text {th }} \mathrm{hr}$. It can be concluded that all clotrimazole cream formulations fulfilled the quality criteria of in-house and pharmacopeias specifications.
\end{abstract}

Key words: In Vitro Evaluation, Clotrimazole, Cream, Spreadability, Extrudability, Ethiopia

Article Info: Received 11 Nov, 2017; Review Completed 21 Dec, 2017; Accepted 22 Dec, 2017; Available online 15 Jan, 2018

Cite this article as:

Debebe D, Gabriel T, Brhane Y, Temesgen A, Nigatu M, Marew T, Comparative in vitro evaluation of brands of clotrimazole cream formulations marketed in ethiopia, Journal of Drug Delivery and Therapeutics. 2018; 8(1):17-22

DOI: http://dx.doi.org/10.22270/jddt.v8i1.1546

*Address for Correspondence

Tesfaye Gabriel, Department of Pharmaceutics and Social Pharmacy, School of Pharmacy, College of Health Sciences, Addis Ababa, University, Addis Ababa, Ethiopia. Email: tesfu.gabriel@gmail.com or tesfaye.gabriel@aau.edu.et; Phone: +251912049154

\section{INTRODUCTION}

In vitro testing of semisolid dosage forms has become important tool and it has been suggested that there should be standard physicochemical testing parameters. In the manufacturing of semisolids, the in vitro release test can show changes in formulation composition and/or manufacturing processes ${ }^{1}$.

Antifungal agents inhibit/impair membrane barrier function (Polyenes), macromolecule synthesis (Flucytosine), interfere with microtubules (Griseofulvin), or inhibit ergosterol synthesis (azole derivatives, morpholines). Azoles include two types: triazoles (Itraconazole, Voriconazole, Posaconazole) and the imidazoles (Clotrimazole). Azoles interfere with an enzyme required for the production of ergosterol, an important component of the fungal cytoplasmic membrane ${ }^{2,3}$.

Clotrimazole is a white or pale yellow, tasteless, crystalline powder which is practically insoluble in water. Clotrimazole has $\mathrm{pH}$ dependent solubility where solubility increases with decreasing $\mathrm{pH}$ due to presence of ionizable imidazole group present in its structure ${ }^{4,5}$.

Clotrimazole was introduced as a topical agent in 1969. It is used for the treatment of superficial candidiasis, and in the skin infections: pityriasis versicolor and dermatophytosis. Clotrimazole may also be used 
occasionally for symptomatic relief of the protozoal infection trichomoniasis when other drugs are contraindicated. It is also effective for prophylaxis in patients undergoing chemotherapy, myeloablative treatment, and transplant recipients and for patients with solid malignant neoplasms 6,7 .

Clotrimazole is safer (especially in pregnant women) than other antifungals currently listed on the WHO Essential Drugs List. It is available without prescription in most countries and this regulatory approval status indicates that the drug is generally recognized as safe ${ }^{8}$.

Clotrimazole is one of the most prescribed drugs for the treatment of fungal infection in many health institutions in Ethiopia. The aim of this work was, therefore, to compare different brands of clotrimazole cream formulations available in Ethiopia.

\section{MATERIALS AND METHODS}

\section{Chemicals and solvents}

The reference/working standard Clotrimazole (99.4\%) pure was received as a gift sample from FMHACA and EPHARM. Potassium dihydrogen phosphate $\left(\mathrm{KH}_{2} \mathrm{PO}_{4}\right)$ (Fizmerk chemicals, India) and $\mathrm{NaOH}$ (Scharlau Chemie
SA, European Union) were obtained from industrial laboratory. Distilled water was used throughout the study.

Cream formulations

Six different Clotrimazole cream containing commercial formulations have been purchased from pharmacy outlets in Ethiopia as indicated in table 1, i.e. Clotrimazole BP $1 \%$ cream labelled to contain 14 gm of clotrimazole (SHANGHAI GENERAL PHARMACEUTICALS CO.,LTD. CHINA), Canesten 1\% cream labelled to contain 20gm of clotrimazole (Bayer PLC., Germany), Candid cream labeled to contain $20 \mathrm{gm}$ of clotrimazole (GLENMARK PHARMACEUTICALS LTD, INDIA \& MAHARASHTRA), Mycoril $1 \%$ cream labeled to contain $20 \mathrm{gm}$ of clotrimazole (Remedica Ltd,Limassol industrial state, Limassol, Cyprus,EU), Candigen $1 \%$ cream labeled to contain $20 \mathrm{gm}$ of clotrimazole (Galentic pharma Pvt.Ltd,India) and Clotri-Denk $1 \%$ cream labeled to contain $20 \mathrm{gm}$ of clotrimazole (DENK PARMA GmbH \& CO. KG, GERMANY).

Table 1: Description of the six clotrimazole cream formulations marketed in Ethiopia

\begin{tabular}{|l|l|l|l|l|l|l|l|l|}
\hline Product & $\begin{array}{l}\text { Brand } \\
\text { name }\end{array}$ & $\%(\mathbf{w} / \mathbf{w})$ & $\begin{array}{l}\text { Labeled } \\
\text { Weight } \\
(\mathbf{g})\end{array}$ & $\begin{array}{l}\text { Cost } \\
(\text { Birr })\end{array}$ & Mfg. date & $\begin{array}{l}\text { Expiry } \\
\text { date }\end{array}$ & $\begin{array}{l}\text { Manufacturer's } \\
\text { Name }\end{array}$ & $\begin{array}{l}\text { Country } \\
\text { of origin }\end{array}$ \\
\hline A & Candid & 1 & 20 & 24.20 & Dec, 2015 & Nov, 2019 & $\begin{array}{l}\text { GLENMARK Pvt } \\
\text { Ltd }\end{array}$ & India \\
\hline B & Candigen & 1 & 20 & 18.10 & Jul, 2016 & Jun, 2019 & $\begin{array}{l}\text { Galentic Pharma } \\
\text { Pvt.Ltd }\end{array}$ & India \\
\hline C & Canesten & 1 & 20 & 117.05 & - & $06 / 2018$ & Bayer Plc. & Germany \\
\hline D & Clotri-Denk & 1 & 20 & 68.00 & Sept, 2016 & Aug, 2019 & $\begin{array}{l}\text { DenkPharma } \\
\text { GmbH\& Co.KG }\end{array}$ & Germany \\
\hline E & $\begin{array}{l}\text { Clotrimazole } \\
\text { BP }\end{array}$ & 1 & 14 & 12.00 & May, 2016 & $\begin{array}{l}\text { May, } \\
2019\end{array}$ & $\begin{array}{l}\text { Shangai General } \\
\text { pharmaceutical } \\
\text { CO.,LTD }\end{array}$ & China \\
\hline F & Mycoril & 1 & 20 & 41.70 & Nov, 16 & Nov, 19 & Remedica Ltd & $\begin{array}{l}\text { Cyprus- } \\
\text { EU }\end{array}$ \\
\hline
\end{tabular}

\section{Methods}

\section{UV calibration curve}

Stock solution was prepared by dissolving $100 \mathrm{mg}$ of clotrimazole in $100 \mathrm{ml}$ solvent containing methanol and PBS 7.4 in the ratio of $75: 25$. From this stock solution, eight different concentrations $(10,20,30,40,50,60,70$ and $80, \mathrm{ug} / \mathrm{ml}$ ) were prepared. The UV absorbance readings of these solutions were measured at $270 \mathrm{~nm}$ using UV/Visible spectrophotometer (CECIL, 1021, 1000 series, England). Methanol was used as a blank. The values of absorbance were recorded and a standard curve was constructed by plotting absorbance against concentration. From this curve a regression line equation was obtained in MS Excel format. The absorbance versus concentration of solutions was plotted and a calibration curve with a linear regression equation of: $\mathrm{Y}=0.0156 \mathrm{X}-0.0345$ (where, $\mathrm{Y}$ is the absorbance and $\mathrm{X}$ is the concentration in $\mathrm{ug} / \mathrm{ml}$ ) and correlation coefficient of 0.9991 was obtained (Figure 1).

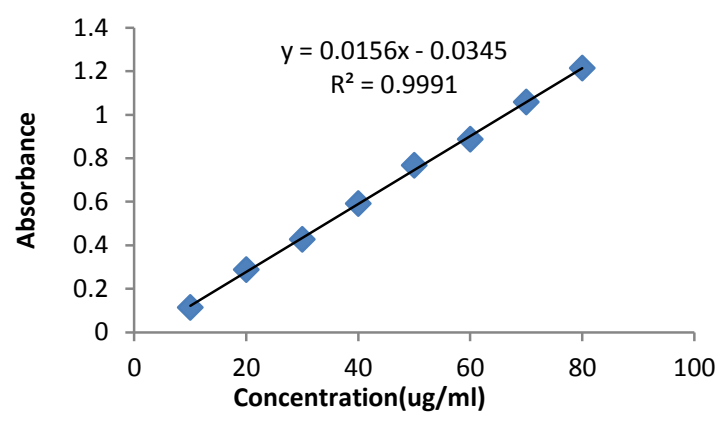

Figure 1: The UV absorption calibration curve of clotrimazole in methanol and PBS (pH 7.4) at $270 \mathrm{~nm}$ with $95 \%$ confidence bands for mean, $\left(r^{2}=0.9991\right)$. 
Physical appearance and homogeneity

The physical appearance and homogeneity of the marketed creams were tested by visual observations after the formulations were set in containers. All the marketed cream formulations were physically inspected for clarity/transparency, color, scent, texture, consistency, and homogeneity. The creams were also evaluated for the presence of any gritty particles ${ }^{7,9}$.

\section{Measurement of pH}

The $\mathrm{pH}$ of various formulations was determined by using digital $\mathrm{pH}$ meter (model PH-210, HANNA instruments, Portugal) which was calibrated prior to use with standard buffered solutions of $\mathrm{pH} \mathrm{4,7}$ and 10. The samples were in contact with the $\mathrm{pH}$ electrode until the reading stabilized. The electrode was thoroughly washed between each determination to remove all traces of the previous sample. The electrode was then rinsed with DW and dried before use. The average of three readings was recorded as $\mathrm{pH}$ value.

\section{Viscosity study}

The measurement of viscosity of each cream formulation was determined by rotational viscometer (KINEMATICA, AG, Type Viscostar plus L, Switzerland) using different spindle numbers L3 and L4 at shear rate of $100 \mathrm{rpm}$ at room temperature. The cream formulations were placed in the sample holder and the suitable spindle selected was lowered perpendicularly into the sample taking care in such a way that spindle does not touch the bottom of the container. The spindle was attached to the viscometer and then it was allowed to rotate at a defined speed at room temperature. The ${ }_{10}$ experiment was carried out in triplicate for each sample

\section{Spreadability of formulations}

The spreadability of each formulation was determined using the following technique with slight modifications: concentric circles of different radii were drawn on graph paper and a $400 \mathrm{~cm}^{2}$ glass plate was fixed onto it. One gram cream formulation was place within a circle of 2.4 $\mathrm{cm}$ diameter pre-marked on a glass plate. Another 400 $\mathrm{cm}^{2}$ glass plate of $123 \mathrm{~g}$ was placed gently on the cream and a standardized weight of $1 \mathrm{Kg}$ was allowed to rest on the upper glass plate for $3 \mathrm{~min}$. The increase in the diameter due to spreading of the formulation was recorded. The spreadability (g.cm. $\mathrm{min}^{-1}$ ) was calculated by using the formula:

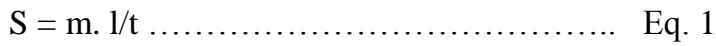

Where: $\mathrm{S}$ is spreadability, $\mathrm{m}$ is the weight of the upper plate and standard weight rested on it $(\mathrm{g}), 1$ is the diameter of the spreading cream $(\mathrm{cm})$, and $\mathrm{t}$ is the time taken $(\min )^{11-13}$.

\section{Extrudability of formulations}

The method adopted for evaluating cream formulation for extrudability was based on the quantity in percentage of cream extruded from tube on application of certain load. The tubes were pressed to extrude the cream through $0.5 \mathrm{~cm}$ opening in 10 seconds and the extrudability of formulations was checked. It was then placed between two glass slides and was clamped. Extrudability was determined by weighing the amount of cream extruded through the tip when a constant load of 1 $\mathrm{Kg}$ was placed on the slides. The percentage of cream extruded was calculated and grades were allotted $(++++$ excellent, i.e., for $>90 \%$ of cream extruded; +++ very good, i.e., for $80-89.9 \%$; ++ good, i.e., for $70-79.9 \%$; + fair, i.e., for $50-69.9 \%$ and 0 for poor, i.e., for $<50 \%$ of cream extruded) ${ }^{14,15}$.

\section{Drug content determinations}

Hundred milligrams of each formulation was taken and dissolved in $100 \mathrm{ml}$ methanol and $10 \mathrm{ml}$ aliquot was diluted in $25 \mathrm{ml}$ volumetric flask. The volumetric flask containing the cream solution was vigorously mixed in order to get complete solubility of the formulation drug. This solution was filtered and drug content was then estimated spectrophotometrically at $270 \mathrm{~nm}$ using methanol as blank ${ }^{16}$. Clotrimazole content was computed as the ratio of actual amount of clotrimazole in the sample to theoretical amount of clotrimazole in the sample, expressed as a percentage ${ }^{17}$.

In vitro release study of marketed clotrimazole cream preparations

In vitro release study was conducted using a glass tube with $100 \mathrm{~mm}$ height, $12.9 \mathrm{~mm}$ outer diameter and 12.1 $\mathrm{mm}$ inner diameter (effective release area of approximately $115 \mathrm{~mm}^{2}$ ) filled with $1 \mathrm{~g}$ of the cream, covered with a cellulose acetate membrane $(0.45 \mu \mathrm{m})$ (which was previously soaked in phosphate buffer of $\mathrm{pH}$ 7.4 for about $12 \mathrm{hr}$ ), sealed with a rubber band (to make water tight), and inverted under the surface ${ }^{18,19}$ of 500 $\mathrm{ml}$ of phosphate buffer of $\mathrm{pH} 7.4$ at $37 \pm 0.5{ }^{\circ} \mathrm{C}$ in a United States Pharmacopeia (USP) dissolution tester apparatus II, with stirring speed of $50 \mathrm{rpm}^{10}$. Samples of $5 \mathrm{ml}$ was withdrawn at 5, 15, 30, 60, 120, 180, 240, 300, $360,480,600$ and $720 \mathrm{~min}$ and replaced with an equivalent amount of fresh receptor medium ${ }^{20}$. The cumulative percent drug release was determined in with validated UV spectrophotometer at $270 \mathrm{~nm}$ and the amount of clotrimazole released from the cream formulations was calculated based on the established standard calibration curve. Each sample was tested six times and mean values taken ${ }^{21-24}$.

\section{RESULTS AND DISCUSSIONS}

\section{Physicochemical evaluation of the cream formulations}

\section{Physical appearance}

Color of all cream formulations was examined against black background. From the results, it is clearly evident that all the cream formulations showed good and smooth homogeneous appearance with white color.

\section{Measurement of $\mathrm{pH}$}

The $\mathrm{pH}$ values of all marketed formulations ranged from 4.0 to 7.0 , among the result which are considered there is no significant difference of the $\mathrm{pH}$ value. However, for formulation $\mathrm{A}$, the $\mathrm{pH}$ was altered and in neutral range so it is not affecting the stability of the preparations as well as the skin. Thus, it can be assumed that the 
formulation is acceptable for topical applications. The other clotrimazole cream formulations, namely Candid (B), Candigen (C) and Canesten (D) and F cream formulations had similar $\mathrm{pH}$ range but Formulation $\mathrm{E}$ lowest $\mathrm{pH}$ value as compared the other.

\section{Viscosity}

Viscosity plays a vital role in the dispensing and formulation of topical formulations. It is related to mechanical and physical properties such as spreadability, consistency and hardness of the preparation which in turn are related to ease of product removal from container, ease of application on the target surface and product feel on the application site ${ }^{25}$.

As shown in Table 2, formulations B, C and D have nearly similar viscosity ranges and formulations $\mathrm{A}$ and $\mathrm{F}$ too are with similar range but with lower viscosity values from the previous three formulations. However Formulation $\mathrm{E}$ was the lowest viscosity value from the other all formulation.

\section{Extrudability}

The extrusion of every formulation from the tube is an important during its application and in patient acceptance. Results from extrudability indicated that cream formulations B, C and D had better extrudability than formulation $\mathrm{A}, \mathrm{E}$ and $\mathrm{F}$ when they were extruded from aluminum collapsible tubes. Due to these results, formulations $\mathrm{A}, \mathrm{E}$ and $\mathrm{F}$ had not extruded quickly from the tubes, whereas, formulations B, C and D extruded quickly from aluminum collapsible tube.

\section{Spreadability}

Spreadability is an essential attribute of topical dosage forms that can affect patient acceptance in terms of ease of application and clinical efficacy. One of the essential criteria for cream is that it should possess good spreadability. Spreadability is an important factor in therapy and it is shown as index of ease of application. The efficacy of topical therapy depends on the patient spreading the formulation in an even layer to deliver a standard dose. The optimum consistency of such a formulation helps ensure that a suitable dose is applied or delivered to the target site. This is particularly important with formulations of potent drugs. A reduced dose would not deliver the desired effect, and an excessive dose may lead to undesirable side effects. The delivery of the correct dose of the drug depends highly on the spreadability of the formulation ${ }^{26}$. The important factors to consider, during evaluating the spreadability of a formulation, include the rate and time of shear produced upon smearing and the temperature of the target site. The parallel-plate method is the most widely used method for determining and quantifying the spreadability of semisolid preparation. It provides accurate, reproducible, and statistically relevant data. The advantages of the method are simplicity and relative lack of expense. On the other hand, the method is not very precise and sensitive, and data which it generates must be manually interpreted and presented ${ }^{11,26}$.

Spreadability is commonly measured by the sample spread diameter or area that is formed upon application of the weight over the sample for a predetermined time period. Spreading of topically applied products was reported to affect drug delivery as reflected by dermatopharmacokinetic outcome such as drug concentration in the stratum corneum (SC). Formulations with higher spreadability values allow ease of application and thereby increased surface area available for drug permeation. A good cream takes less time to spread and will have high spreadability $5,27,28$.

Results of spreadability as shown in Table 3.1 showed that cream $\mathrm{F}$ gave better spreadability from other clotrimazole cream but formulation $\mathrm{C}$ gave lowest spreadability value from the other formulation. The remaining formulation which is medium viscosity value as compare to the other above two formulations.

\section{Drug content}

The clotrimazole content was found to be in the range of $90 \%-110 \%$ in the cream formulations. Therefore, it may be assumed that these formulations were applicable for topical application. Formulation $\mathrm{A}$ had highest and formulation $\mathrm{E}$ had lowest drug content value from the results obtained. The rank order of drug content was: formulation $\mathrm{A}>\mathrm{B}>\mathrm{D}>\mathrm{C}>\mathrm{F}>\mathrm{E}$.

Table 2: Physico-chemical and drug content evaluation of the six clotrimazole cream formulations marketed in Ethiopia

\begin{tabular}{|c|c|c|c|c|c|c|c|c|}
\hline $\begin{array}{l}\text { Brand } \\
\text { name }\end{array}$ & $\begin{array}{l}\text { Labeled } \\
\text { weight } \\
(\mathrm{g})\end{array}$ & $\begin{array}{l}\text { Net weight } \\
(\mathrm{g}) \\
(\text { Mean } \pm \mathrm{SD})\end{array}$ & $\begin{array}{l}\text { Physical } \\
\text { appearance }\end{array}$ & $\begin{array}{l}\mathrm{pH} \\
(\text { Mean } \pm \mathrm{SD})\end{array}$ & $\begin{array}{l}\text { Viscosity } \\
(\mathrm{cP}) \text { at } 100 \\
\text { rpm } \\
(\text { Mean } \pm \text { SD) }\end{array}$ & Extrudability & $\begin{array}{l}\text { Spreadability } \\
\text { (g.Cm/min) } \\
(\text { Mean } \pm \text { SD) }\end{array}$ & $\begin{array}{l}\text { Drug } \\
\text { Content }(\%) \\
(\text { Mean } \pm \text { SD) }\end{array}$ \\
\hline Candid & 20 & $24.06 \pm 0.01$ & White & $6.68 \pm 0.09$ & $8114 \pm 23.6$ & + & $1773 \pm 93$ & $108.52 \pm 0.04$ \\
\hline Candigen & 20 & $23.82 \pm 0.06$ & White & $6.32 \pm 0.1$ & $8153 \pm 11.4$ & +++ & $2146 \pm 95$ & $106.16 \pm 1.83$ \\
\hline Canesten & 20 & $24.84 \pm 0.03$ & White & $6.09 \pm 0.1$ & $8152 \pm 15.3$ & +++ & $1304 \pm 65$ & $95.67 \pm 0.03$ \\
\hline $\begin{array}{l}\text { Clotri- } \\
\text { Denk }\end{array}$ & 20 & $23.73 \pm 0.01$ & White & $6.00 \pm 0.07$ & $8157 \pm 27.73$ & +++ & $1497 \pm 84$ & $100.38 \pm 0.99$ \\
\hline Clotrimazol & 14 & $17.24 \pm 0$ & White & $4.45 \pm 0.21$ & $7661 \pm 127.6$ & ++ & $1398 \pm 98$ & $90.82 \pm 0.05$ \\
\hline Mycoril & 20 & $24.55 \pm 0.03$ & White & $5.94 \pm 0.18$ & $8050 \pm 31.2$ & ++ & $3057 \pm 1543$ & $91.47 \pm 1.72$ \\
\hline
\end{tabular}




\section{In vitro release study of marketed clotrimazole cream preparations}

In vitro dissolution methods are developed to evaluate the potential in vivo performance of a semisolid dosage forms, and as quality control tests demonstrating the appropriate performance of drugs products. In recent years, the convergence of the increased understanding of the physiological environment and processes of absorption, critical deconstruction of the mechanisms of release from formulations, and improved computational tools has led to a more sophisticated discussion of the role of dissolution testing in drug product design and control. It is clear that meaningful results and interpretation of dissolution data can be achieved only when the biopharmaceutical and physical properties of the drug products are well understood, and that test methods are properly established through studies during formulation and manufacturing process design and clinical development ${ }^{18}$.

It is expected that drug release might be influenced by cream viscosity. As the viscosity of the cream increased, the release of the drug was expected to be slower. Complete drug release $(100 \%)$ was not achieved at the $12^{\text {th }} \mathrm{hr}$ for all marketed formulation. Cumulative amount of drug released in dissolution medium showed extremely significant difference $(\mathrm{P} \leq 0.0005)$ which could be because of the differences in surfactant concentration. This effect may be strengthened by the ability of these emulsifying agents to lower the interfacial tension between oily and aqueous layer in the dispersion medium, increasing the hydrophilicity of the cream which in turn increases penetration of dissolution medium into the clotrimazole structure and then increasing the amount of drug released ${ }^{18}$.

Drug release from all formulations was slow in the first $6 \mathrm{hrs}$. After the $6^{\text {th }} \mathrm{hr}$, steady drug release continued for formulation $\mathrm{D}$ and $\mathrm{E}$. Fast drug release was observed in formulations A (Candid) and B (Candigen), whereas for the formulations $\mathrm{C}$ (Canesten), D and $\mathrm{E}$, steady drug release pattern was observed after the $6^{\text {th }} \mathrm{hr}$.

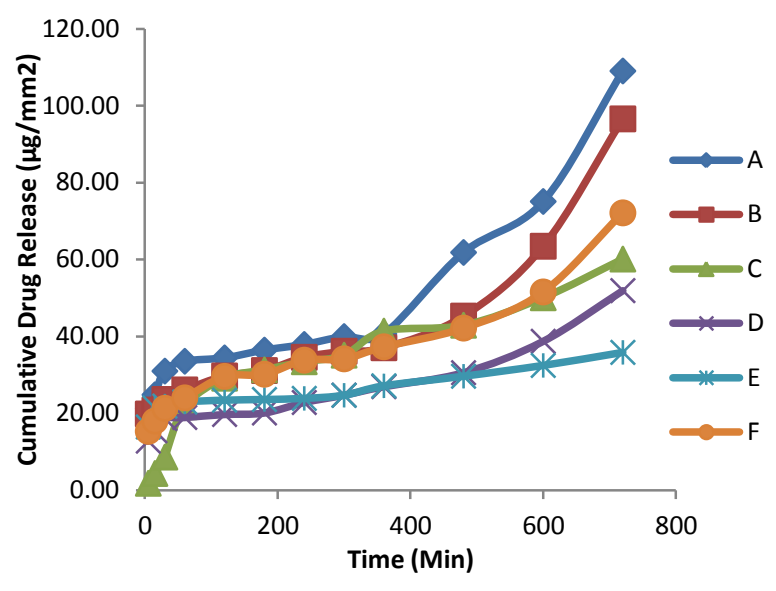

Figure 2: In vitro release evaluation of six clotrimazole cream formulations marketed in Ethiopia

\section{CONCLUSIONS}

The study results indicated that marketed clotrimazole creams included in this study seem to have showed good and smooth homogeneous appearance of white color without any gritty particles. Cream formulation B, C and D showed better extrudability as compared to the other formulations. Cream formulation D exhibited higher viscosity values than other formulations, whereas formulation $\mathrm{E}$ showed lowest viscosity value. Fast drug release was observed in formulation A but formulation $\mathrm{E}$ showed slowest drug release. Finally, it can be concluded that all clotrimazole cream formulations fulfilled the quality criteria of in-house and pharmacopeias specifications.

\section{ACKNOWLEDGEMENTS}

The authors are grateful for the opportunity provided by Addis Ababa University. Food, Medicine and Health Care Administration and Control Authority (FMHACA) and Ethiopian Pharmaceutical Manufacturing (EPHARM SH CO) are acknowledged for providing us clotrimazole reference/working standard. However, this research did not receive any specific grant from funding agencies in the public, commercial, or not-for-profit sectors.

Abbreviations
BP
CYP
DW
EPHARM SH CO
FMHACA
MPO
PBS
USA
USP
USP-NF
UV
WHO

British Pharmacopeia

Cytochrome P450

Distilled Water

Ethiopian Pharmaceutical Manufacturing

Food, Medicine and Health Care Administration and Control Authority

Myeloperoxidase

Phosphate buffered solution

United State of America

United States Pharmacopeia

United States Pharmacopoeia-National Formulary

Ultraviolet

World Health Organization 


\section{REFERENCES}

1. Carbo M., Schultz T.W., Wong GK, Van BG. Development and Validation of In Vitro Release Testing Methods for Semisolid Formulations. Pharm. Tech. 1993; 112-128.

2. Gelone SA, O'Donnell J. Anti infectives. In Remington the science and practice of pharmacy, 21st Edition ed, Troy DB, 2006; pp 1626-1684. Baltimore: Lippincott Williams and Wilkins.

3. Lorand T. and Kocsis B. Recent advances in antifungal agents. Mini-Rev Med Chem 2007; 7:900-911.

4. Hoogerhaide J.G. and Wyka B.E. Clotrimazole. In: Analytical profiles of drug substances. Volume 11. Floret, K. (Editor). Academic Press INC. New York. 1982.

5. Bachhav Y.G. and Patravale V.B. Microemulsion-Based Vaginal Gel of Clotrimazole: Formulation, In Vitro Evaluation, and Stability Studies. AAPS Pharm Sci Tech, 2009; 10: 476-482.

6. Czerninski R., Sivan S., Steinberg D., Gati I., Kagan L. and Friedman, M. A novel sustained-release clotrimazole varnish for local treatment of oral candidiasis. Clin Oral Invest 2010; 14:71-78.

7. Singh M.P., Nagori B.P., Shaw N.R., Solanki R. and Tiwari M. A Comparison Study of QC Parameters of Marketed Topical Gel Formulations. Int J Pharmace Res Bio-Sci 2014; 3: 471-481.

8. Bero L.A. Review of Application of Clotrimazole for topical or intravaginal use in vulvovaginal candidiasis. Selection and Use of Essential Medicines, WHO. 2005

9. Mohamed M.I. Optimization of Chlorphenesin Emulgel Formulation. The AAPS 2004; J 6: 1-7.

10. El-Houssieny, B.M. and Hamouda, H.M. Formulation and evaluation of clotrimazole from pluronic F127 gels. Drug Discov Ther, 2010; 4(1), 33-43.

11. Jelvehgari M., Rashidi M.R., and Mirza Mohammadi S.H. Adhesive And Spreading Properties of Pharmaceutical Gel Composed of Cellulose Polymer. Jundish J Nat Pharmace Prod 2007; 2: 45-58.

12. Nair R., Sevukarajan M., Mohammed B., and Kumar J. Formulation of Microemulsion based vaginal gel in-vitro and in-vivo evaluation. Der Pharmacia Lettre, 2010; 2: 99-105.

13. Prajapati B.G. and Patel M.M. Crosslinked chitosan gel for local drug delivery of clotrimazole. J Sci Tec 6: 43-52.

14. Das K., Dang R. and Machale M.U. Formulation and Evaluation of a Novel Herbal Gel of Stevia Extract. Iranian J Derm 2009; 12: 117-122.

15. Najmuddin M., Mohsin A.A., Khan T., Patel, V. and Shelar S. Formulation and Evaluation of Solid Dispersion Incorporated Gel of Ketoconazole. Res J Pharm Bio and Chem Sci 2010; 1: 406-412.

16. Akhtar N., and Pathak K. Cavamax W7 Composite Ethosomal Gel of Clotrimazole for Improved Topical Delivery: Development and Comparison with Ethosomal Gel.
AAPS PharmSciTech. 2012; 13(1), 344-355. doi: 10.1208/s12249-012-9754-y.

17. Souto E., Wissing S., Barbosa C. and Muller R. Development of a controlled release formulation based on SLN and NLC for topical clotrimazole delivery. Int J Pharm 2004; 278:71-7.

18. Sabri L.A., Sulayman H.T. and Khalil Y.I. An Investigation Release and Rheological Properties of Miconazole Nitrate from Emulgel. Iraqi J Pharm Sci, 2009; 18: 26-31.

19. Hashem F.M., Shaker D.S., Ghorab M.K. Nasr M. and Ismail A. Formulation, Characterization, and Clinical Evaluation of Microemulsion Containing Clotrimazole for Topical Delivery. AAPS PharmSciTech, 2011; 12(3), pp.879-886. Available at: http://www.springerlink.com/index/10.1208/s12249-0119653-7.

20. Ueda C.T., Shah V.P., Derdzinski K., Ewing G., Flynn G., Maibach, H., Marques, M., Rytting, H., Shaw, S., Thakker, K. and Yacobi, A. Topical and Transdermal Drug Products. Pharmacopeial Forum 2009; 35: 750 - 765.

21. Lopes L.B., Collett J.H., Vitória M.L.B. and Bentley L.B. Topical Delivery of Cyclosporin A: an In Vitro Study using Monoolein as a Penetration Enhancer. Eur J Pharm Biopharm 2005; 60: 25-30.

22. Gopi C., Kumar V.T.M. and Dhanaraju M.D. Design and Evaluation of Novel Ibuprofen Gel and its Permeability Studies. Int J Biopharm 2010; 1: 82-84.

23. Chen M., Liu X. and Fahr A. Skin Penetration and Deposition of Carboxyfluorescein and Temoporfin from Different Lipid Vesicular Systems: In Vitro study with Finite and Infinite Dosage Application. Inter J Pharm 2011; 408: 223-234.

24. Sanna V., Peana A.T. and Moretti M.D.L. Effect of Vehicle on Clotrimazole Permeation from New Topical Formulations, In Vitro and In Vivo Studies. Current Drug Delivery 2009; 6: 93 100 .

25. Nawaz, A., Jan, S.U., Khan, N.R., Hussain, A. and Khan, G.M. Formulation and in vitro evaluation of clotrimazole gel containing almond oil and Tween 80 as penetration enhancer for topical application. Pak J Pharm Sci, 2013; 26(3), pp.617622.

26. Garg A., Aggarwal D., Garg S. and Singla A.K. (2002) Spreading of Semisolid Formulations: An Update. Pharmaceutical Technology. Circle/eINFO 74.

27. Chow K.T., Chan L.W. and Heng P. Characterization of Spreadability of Non- aqueous Ethylcellulose Gel Matrices Using Dynamic Contact Angle. J Pharm Sci 2008; 97: 34673482 .

28. Chaudhary H., Kohli K., Amin S., Rathee P. and Kumar V. Optimization and Formulation Design of Gels of Diclofenac and Curcumin for Transdermal Drug Delivery by BoxBehnken Statistical Design. J Pharm Sci 2010. DOI 10.1002/jp 22292. 